\title{
Perspectives on Confidential Care for Adolescent Girls
}

\author{
M. Diane McKee, MD, MS \\ Lucia F. O'Sullivan, $P b D^{1}$ \\ Catherine $M$. Weber, $P b D^{2}$ \\ ${ }^{1}$ Department of Family and Social Medi- \\ cine, Albert Einstein College of Medicine, \\ Bronx, NY \\ ${ }^{2}$ Department of Family Medicine, Univer- \\ sity of Connecticut School of Medicine, \\ Farmington, Conn
}

\begin{abstract}
PURPOSE We wanted to obtain perspectives of mothers and daughters on facilitators of and barriers to with adolescent girls' timely access to risk-appropriate reproductive care.

METHODS We conducted 5 separate focus groups with Latina and black mothers and their adolescent daughters. All participants resided in impoverished neighborhoods of New York City. Participants addressed mothers' roles in helping girls initiate gynecologic care, perceived role of physicians in daughters' sexual health, including the provision of confidential care, and perceived need for girls' gynecologic care. Data were analyzed using qualitative data analysis methods.
\end{abstract}

RESULTS Mothers see themselves as their daughters' primary protectors against daughters' poor reproductive outcomes. Many believe that confidential care promotes risky behavior and undermines mothers' efforts to protect girls. Mothers endorse facilitating gynecologic care and entering alliances with physicians but see the need for care as arising only after girls' sexual debut. Unfortunately, maternal awareness of sexual activity is low. Adolescent girls express considerable discomfort around reproductive health care and negotiating maternal involvement, and they fear breaches in confidentiality.

CONCLUSIONS A lack of trust in health care clinicians and the mother's gatekeeper role are key barriers to girls' transition to reproductive care. Consistently including a confidential component to health care visits in early adolescence, with preparation for both mothers and daughters, may reduce the distrust and discomfort.

Ann Fam Med 2006;4:519-26. DOI: 10.1370/afm.601.

\section{INTRODUCTION}

dolescent girls who live in impoverished urban settings are at far
higher risk for negative health consequences of sexual activity
compared with national norms. ${ }^{1,2}$ Earlier onset of sexual activity, ${ }^{3}$ inadequate birth control, ${ }_{1}^{4}$ and older sexual partners ${ }^{5}$ contribute to higher rates of sexually transmitted infections ${ }^{6}$ and pregnancy. ${ }^{7}$ This disparity may reflect complex associations of poverty, social inequalities, less access to preventive services, and neighborhood characteristics. ${ }^{8}$ Large northeastern US urban centers have become epicenters of sexually transmitted disease and teenage pregnancy epidemics. ${ }^{9}$ Health care professionals are challenged with developing innovative means of helping urban families overcome obstacles to reproductive health care.

Adolescents often have unmet health needs ${ }^{10,11}$ especially after sexual debut. $^{12,13}$ In a recent study, only $45 \%$ of sexually active urban girls had initiated gynecologic screening. The delay between onset of sexual activity and screening averages 13 months. ${ }^{14}$ Unfortunately, the best predictor of initial screening is experiencing a sexually transmitted infection or unwanted pregnancy. Adolescents have considerable need for confidential care ${ }_{1}^{15}$ but often they cannot overcome barriers to needed services.

Sexual health research during the last 2 decades has focused much attention on the influence of family, particularly with regard to initiation of sexual 
activity, contraceptive use, and pregnancy. ${ }^{16}$ Open communication about sex is associated with better sexual health outcomes for adolescents, ${ }^{17-20}$ although far fewer studies have specifically addressed urban minority families. ${ }^{21-24}$ Mothers are clearly the primary communicators about sex in most families. ${ }^{25}$ Both mothers and daughters emphasize the importance of discussing sexuality and reproductive health, ${ }^{24,26,27}$ yet both report that it is challenging and most often inadequate. ${ }^{28,29}$ Little is known about the role of the family in facilitating gynecologic care for adolescents. In one qualitative study of urban minority families, girls emphasized the important role that mothers play in seeking health care before sexual debut, but they reported difficulty transitioning from trusted familial sources of advice and care (especially mothers) to other appropriate sources of care after onset of sexual activity. ${ }^{13}$

Adolescents have considerable need for confidential reproductive care but often do not seek it. Given the heightened risk of negative reproductive health sequelae that adolescent girls face, research is needed to better understand the factors inhibiting their onset of gynecologic care. Previous research has not explored the role that mothers play as facilitators of gynecologic care for adolescent girls, nor have views of confidential care among urban adolescents or their mothers been reported. We invited both mothers and daughters to participate separately in focus groups in a preliminary exploration of their perspectives on strategies to encourage adolescent girls to obtain risk-appropriate and timely care. The protocol focused on social and systemic barriers associated with girls' access to and use of care, taking a culturally sensitive approach to exploring these issues. We will develop primary care interventions to improve adolescent girls' care based on these and related findings.

\section{METHODS}

This study was conducted in 5 community health centers $(3$ family medicine staffed and 2 medicine-pediatrics staffed) located in Bronx, NY. These practices provide family-centered care to a largely minority, lowincome community. The Institutional Review Boards of both Albert Einstein College of Medicine and Montefiore Medical Center approved this study.

\section{Recruitment}

The study sample comprised mothers and their adolescent daughters aged 16 to 19 years. We recruited mothers because they are the primary communicators and health care coordinators in the family arena, ${ }^{30}$ and because data collection from multiple informants increases the value of the information. ${ }^{31}$ We included older adolescent daughters because they are more likely than younger girls to be sexually active and to have reproductive health needs. Using the practices' clinical information systems, we identified women who had visited 1 of the 5 health centers within the previous 4 months. These women were presumed eligible if they were members of an ethnic minority and had a daughter between the ages of 16 and 19 years who had ever been seen at the health center. Letters signed by the women's primary care physician were mailed to 228 women believed to meet these criteria. Table 1 displays rates of contact and refusal. Black and Latina women had similar rates of successful contacts (57\% and 55\%, respectively) and of declining participation (28\% and $22 \%$, respectively). No eligible daughter declined.

\section{Data Collection}

Mothers and daughters participated in their respective focus groups on separate days. We chose focus groups rather than individual interviews because we believed participants' interactions would allow greater in-depth exploration of a range of related perspectives that might help identify key variables to be later operationalized quantitatively. ${ }^{32}$ Mothers provided consent to recruit daughters into the study. All participants provided signed informed consent before entering the study, then completed a background questionnaire that included sexual health and general care items. Mothers completed a few additional items assessing their knowledge of their daughters' sexual experience. Participants were informed that the discussion would be tape recorded and that the audiotape would be heard only by project staff before being transcribed, after which it would be erased. Girls were assured that their mothers, in particular, would never hear the audiotapes. No identifying information was used during the sessions, and participants were asked to maintain the privacy of the others after the session was completed. Focus groups were conducted in Spanish (by native Spanish speakers) or English by graduate-level female facilitators matched by ethnicity to participants.

\begin{tabular}{|lcc|}
\hline Table 1. Study Recruitment and Refusal Rates \\
\hline Recruitment Characteristics & $\begin{array}{c}\text { Total } \\
\text { Mothers } \\
\text { No. (\%) }\end{array}$ & $\begin{array}{c}\text { Total } \\
\text { Daughters } \\
\text { No. }\end{array}$ \\
\hline Dyads presumed eligible & 228 & - \\
Returned opt-out card & $13(6)$ & - \\
Attempted to reach & 180 & - \\
Reached by telephone (after & $79(44)$ & - \\
repeated efforts) & 20 & - \\
Found to be ineligible after contact & $19(32)$ & 0 \\
Refused participation & 40 & 20 \\
Intended to attend a group & 21 & 18 \\
Actually attended a scheduled group & & \\
\hline
\end{tabular}


Following guidelines for conducting focus groups, ${ }^{32}$ facilitators used a list of questions to direct the discussions while allowing participants to explore in depth those issues they found most interesting. The session facilitators phrased the open-ended questions using idiomatic terms consistent with those used by participants during the session, and questions were presented in ways congruent with the flow of the conversation. Sessions lasted approximately 90 minutes. Immediately after each session, the investigators reviewed the session with the facilitator, including an evaluation of the flow of the conversation and participants' verbal and nonverbal reactions to issues presented. Session facilitators transcribed audiotapes of the focus group sessions in their original language and checked for accuracy. Spanish transcripts were translated verbatim into English by the session facilitator and proofed again for accuracy by bilingual members of the project staff.

\section{Focus Group Guides}

Based on gaps noted in our previous research and the existing literature, we developed appropriate questions and probes relating to each group in consultation with experts in psychosocial qualitative assessment at our research center. All questions were open-ended and designed to be neutral in content and tone to minimize the extent to which the session facilitator might influence participants' responses. For each group we developed a focus group guide exploring 3 primary areas. The first area was mothers' roles in helping girls initiate gynecologic care. Specific prompts addressed the nature, focus, and quality of their sexual health communication, mothers' interactions and experiences with doctors and health centers regarding their daughters' care (with a focus on confidential care), and perceived barriers and facilitators regarding open exchange in these situations. The second area was the perceived role of physicians in daughters' sexual health, including the provision of confidential care and ideal partnerships with physicians to meet girls' needs, with prompts regarding the timing, perceived risk and benefits, and possible strategies for partnering with physicians. The third primary area addressed perceived need for girls' gynecologic care, with prompts regarding the nature and adequacy of preparation for visits, available resources, and perceived importance of girls' sexual status before delivery of care. The only difference between the mother's and daughter's guides was in phrasing the questions (referring to the respondents' own experiences vs those of their mothers or daughters).

\section{Data Analysis}

The analysis team included a family physician, a psychologist, and a sociologist. The team used an editing approach in which each independently identified key themes related to the content areas of interest. ${ }^{33}$ After discussion and refinement, the team developed and applied a final coding scheme, using NVivo software, version 2 (NVivo, QRS International, Doncaster, Aust) to facilitate the retrieval of text passages. Coding was $90 \%$ consistent among the 3 analysts. Coding differences were explored in meetings until consensus was achieved. ${ }^{34}$ Convergence and divergence of themes were explored across groups, then between mothers and daughters. Illustrative quotes were selected across groups, and the sources are referenced by whether they were Latina or black.

A number of themes emerged from our grounded analysis of each of our 3 primary areas of focus: perceptions of girls' need for care, implications of confidential care, and perceptions of the role of physicians. After making the first provisional definition of a category, additional excerpts were sought to help refine the category and outline the various themes within it. The categories described below comprise the themes, each of which is illustrated with quotes drawn from the excerpted sections of the transcripts. Differences between ethnic groups were recorded on the basis of these themes.

\section{RESULTS}

\section{Sample Characteristics}

Table 2 displays mothers' characteristics. Three focus groups were conducted with mothers: 1 with Spanish-

Table 2. Demographic Information of Black ( $n=8)$ and Latina $(n=14)$ Mothers

\begin{tabular}{lcc}
\hline Demographic Characteristics & $\begin{array}{c}\text { Black } \\
\text { No. }\end{array}$ & $\begin{array}{c}\text { Latina } \\
\text { No. }\end{array}$ \\
\hline Age, years & & \\
$30-40$ & 6 & 3 \\
$41-50$ & 2 & 8 \\
$50+$ & 0 & 1 \\
Born in United States & 6 & 9 \\
Employment status* & & \\
In school part-time & 0 & 1 \\
In school full-time & 1 & 0 \\
Employed part-time & 1 & 3 \\
Employed full-time & 3 & 6 \\
Homemaker & 4 & 3 \\
Currently receiving public assistance & 3 & 4 \\
Estimated family Income & & 8 \\
\$0-\$20,000 & 4 & 4 \\
$\$ 21,000-\$ 40,000$ & 3 & 1 \\
$\$ 41,000-\$ 60,000$ & 0 & 0 \\
$\$ 61,000+$ & 1 & $3.1(2-9)$ \\
No. of children, mean (range) & $3.5(2-8)$ & \\
No. of people living on income, & $4.4(2-7)$ & \\
mean (range) & & \\
* Participants could check more than 1 option. & & \\
\hline
\end{tabular}


speaking Latinas $(n=6)$, 1 with English-speaking Latinas $(\mathrm{n}=8)$, and 1 with black women $(\mathrm{n}=8)$. Participants resided in neighborhoods with family incomes below national poverty levels. Nearly one third (32\%) of the mothers reported receiving public assistance. Eight mothers believed that their daughters had never engaged in intercourse, 8 reported that they knew their daughters had, and the remaining 6 mothers (all Latinas) indicated that they did not know. Two focus group sessions were conducted with the adolescent daughters (Table 3): 1 with Latina girls $(\mathrm{n}=12)$ and 1 with black girls $(n=6)$. Two thirds $(n=12,67 \%)$ of the girls reported past sexual intercourse. Of those

\section{Table 3. Sexual Behavior and Reproductive Care Histories of Black $(n=6)$ and Latina ( $n=12$ ) Daughters}

\begin{tabular}{|c|c|c|}
\hline History Characteristics & $\begin{array}{c}\text { Black } \\
\text { No. }\end{array}$ & $\begin{array}{l}\text { Latina } \\
\text { No. }\end{array}$ \\
\hline \multicolumn{3}{|l|}{ Relationship history } \\
\hline Boyfriend in past & 6 & 10 \\
\hline Boyfriend at time of study & 2 & 7 \\
\hline \multicolumn{3}{|l|}{ Sexual history } \\
\hline Sexual activity (ever) & 4 & 8 \\
\hline Sexual activity (prior 2 months) & 2 & 7 \\
\hline Sexual intercourse (ever) & 4 & 7 \\
\hline Sexual intercourse (prior 2 months) & 2 & 7 \\
\hline Number of intercourse partners & $\begin{array}{c}1 \\
\text { (3 missing) }\end{array}$ & $\begin{array}{l}1.8 \text { (mean) } \\
1-3 \text { (range) }\end{array}$ \\
\hline \multicolumn{3}{|l|}{ Reproductive care history } \\
\hline Past gynecologic examination & 2 & 5 \\
\hline Past pregnancy & 1 & 2 \\
\hline Past pregnancy concern & 2 & 5 \\
\hline Past birth & 0 & 2 \\
\hline \multicolumn{3}{|l|}{$\begin{array}{l}\text { Type of contraceptives/prophylactic } \\
\text { use at last intercourse* }\end{array}$} \\
\hline Condoms & 4 & 4 \\
\hline Withdrawal & 1 & - \\
\hline Birth control pills & - & - \\
\hline Rhythm & - & - \\
\hline Vaginal sponge & - & - \\
\hline Foam, jelly, cream, or suppositories & - & - \\
\hline Diaphragm & - & - \\
\hline Intrauterine device (IUD) & - & 1 \\
\hline Depo-Provera (the shot) & - & 2 \\
\hline Norplant & - & - \\
\hline Contraceptive film & - & - \\
\hline Other & - & - \\
\hline Don't know & - & - \\
\hline None of the above & - & 1 \\
\hline No response & - & 1 \\
\hline \multicolumn{3}{|l|}{$\begin{array}{l}\text { Mothers' awareness of girls' sexual } \\
\text { experience }\end{array}$} \\
\hline Mother knows of sexual experience & 3 & 5 \\
\hline Told mother about sexual experience & 2 & 4 \\
\hline
\end{tabular}

who had experienced intercourse, fewer than one half indicated that their mothers were aware of it.

\section{Perceptions Regarding the Need for Gynecologic Care}

Mothers uniformly expressed strong commitment to a revered social position as their children's protectors and their responsibilities to their daughters' health. This role entails constant vigilance to ward off threats, including early sexual experience and pregnancy, associated with living in a dangerous urban environment. This topic generated a lot of exchange among mothers. One woman said, "We're the only ones that can protect our children from whatever else happens" (black [B]). Another stressed needing to keep informed about all aspects of their children's lives: "Because if you're responsible for your child until the age of 21, you're also responsible to know what's going on in your child's life" (Latina [L]).

These responsibilities extend to the clinical realm, where many mothers described making girls' appointments with physicians after learning of their daughters' sexual debut, accompanying girls to their appointments, and attempting to oversee physician contact with their daughters. Four mothers expressed concern that their daughters were not yet able to make good decisions without their intervention: "The doctor can talk to them to a certain point, but girls are not equipped to make a decision. You know? And they could make the wrong decision, and the mother could make a big difference ... can turn the kid around. No matter what, we're their mothers" (L).

Girls recognized the need for care related to reproductive health, but they also acknowledged that most girls did not seek care despite needing to do so. In describing reasons why girls avoided care seeking, almost all girls saw barriers associated with difficulty acknowledging personal risk, negotiating the needed disclosure, or overcoming fears of being stigmatized or rejected by their mothers. Latina girls appeared somewhat more sensitive to potential stigma associated with being known to have become sexually active. They talked about the importance of being an example to other family members by remaining a virgin. One told her group, "They want me to be an example. My mom had me when she was 15 years old, so they were always on me. Ever since I started getting older, like, they were, like, 'Okay, she's getting older. Let me protect her and watch her'" (L).

A few girls believed that seeking gynecologic care was an index of maturity, associated with taking responsibility of caring for their bodies. As one said, "To me, if you're grown enough to open your legs, you're grown enough to go to the doctor" (L). They acknowledged that seeking such care required a certain level of cour- 
age: to overcome the obstacles inherent in seeking health care, to face the possibility of a serious health problem, and to reveal one's sexuality to adults, including possibly one's mother.

A minority of girls acknowledged some advantages to mothers' involvement in their health care, including access to transportation, knowledge of details of the medical history, insurance coverage, and negotiating difficult systems for making appointments; a few girls were able to empathize with their mothers regarding concerns about early childbearing or inappropriate sexual contact. Even so, the girls' empathy had limits. An extremely common theme in the girls' groups was selective or edited communication with their mothers to ensure some privacy in their sexual lives and to resist the often high level of control exercised by mothers. One girl explained, "And [my Mom] goes, 'But you tell me everything!' I said, 'Ma, I tell you everything to a certain extent.' She'll take it personal, you know? That's why I like go to the doctors by myself so that she don't know" (B). These opinions generated a great deal of sympathetic and animated exchange. Others described being secretive as a way to protect their relationship with their mothers. As one said, "I'd be more worried if I was pregnant only because we come up with this relationship where I said I wasn't gonna [have sex], and we have that connection, so I'd kinda be, if I got pregnant, betraying our relationship" (B). Along similar lines, another stated: "For me, I don't want my mother to look at me differently. Cause she always looks at me like I'm her baby.... And now that I'm growing up, it's hard for her to understand that... I don't want to disappoint her" (L).

\section{Implications of Confidential Care}

Mothers expressed considerable discomfort with confidential care, in part related to concerns that girls required their protection. Mothers were dismayed by direct questioning about sexual matters, especially for girls not yet sexually active. Such questions were perceived as far too intrusive, possibly sexualized, and often developmentally inappropriate. For example, one mother exclaimed to her group:

"[The doctor said] to my girl who has 16 years, 'In which of your 3 parts have you had sex?' Three parts! My daughter didn't know about that. She told her, 'oral, anal, or from your mouth.' My daughter was in shock. They undress her, when a child has never been asked to get undressed ... too much of a bad habit. Because it's a child" (L).

This comment generated a lot of exchange among the mothers, many of whom were concerned about their daughters' exposure to graphic content and to physical examination:
"With my older daughter I stepped outside, and I felt horrible! Horrible because [the doctor] took me out of something that my daughter was going to learn about the first time. That someone was going to see her naked for the first time. They were going to touch her...W When they took her to the adolescent clinic, this doctor came like a know-it-all. 'Go outside, wait outside.' It's horrible!" (L).

Mothers expressed considerable distrust about the care that might be provided to their daughters during confidential encounters. Black mothers in particular were concerned that physicians may offer experimental or unproven treatments, or let financial interests outweigh concern for the adolescent's health: "I hate to be kind of cynical about this, some doctors promoting more work for the medical people ... like telling your child that it's all right to have sex or, 'Do you want birth control pills?"' (B).

Although about one half of the girls in both groups stressed the value of confidential care and keeping some things private from their mothers, some of these same girls and others indicated that confidential care (routine and gynecologic) was awkward and for many, extremely uncomfortable. This participant described a situation in which confidential care was introduced poorly by the clinician:

"The doctor had asked me..., 'Do you want your mom to leave, or do you want your mom to stay?' I looked at my mother, and then I looked at my doctor. She had a paper in her hand and a pen. Looked at my mother, and then [mom] said, 'Do you want me to leave?' I had to think, like, what if she asked me a certain question, and I didn't tell my mother I was having sex yet? So ... I was like, 'Yeah.' She left ... but I felt I wanted my mom to stay... but I was scared because I didn't know what [the doctor] was gonna ask me" (B).

Another way in which the process can be difficult for girls is that they expect to be asked about the time alone with the clinicians by their mothers:

"As soon as I get out of the room, she's gonna grill me anyway about, you know, what happened... I did not tell her everything anyways, so. When she asks me questions, I tell her. But I won't tell her, like, what I don't wanna tell her. I tell her part of the truth" (B).

A few daughters in both groups also reported discomfort on the part of their physicians, seeing physicians as going through the motions and being unwilling to personalize the attention they provide.

"I feel like it's a questionnaire. They're not asking me, like, 'I want to make sure you're healthy.' They asking me, like, 'I have a bunch of questions that I'm supposed to ask you.' It's the same attitude that makes you feel, like, 'No, I don't want to tell you.' And it's like to clear their checklist" (B). 
Girls fear breaches in confidentiality, a theme that received more attention in the group of black girls than in the Latina group: "Yeah, 'cause maybe you can think that you have a certain bond with you doctor, and the doctor doesn't think that they have that certain bond with you and then go tell your parents, and it becomes a big thing" (B). Given the particularly sensitive nature of the care required, some girls were dismayed by their experiences with physicians who failed to recognize their limited sexual experience, need for reassurance, inhibitions, or discomfort. There were many limits to full disclosure. One said, "I don't think I would feel completely comfortable telling my doctor everything, cause it's like a stranger. I mean they know my history, but not everything. I wouldn't go to them and tell them anything sexual" (B). Another told her group, "I'm gonna talk to her (doctor) about the whole problem. You can't talk to your doctor about your feelings" (B).

\section{Perceptions of the Role of Physicians}

Notable among both mothers' and daughters' discourses was a common view that the physician's role was reactive (becoming involved after sexual debut) rather than proactive or preventive. One mother noted, "We are making the appointment since she's with her boyfriend, and she's gonna' keep having sex. I keep telling her, 'See a doctor. I want you to go to a doctor.' I don't want her to get pregnant" (L). In addition, some mothers tended to focus on the physicians' roles as educator regarding consequences of sexual activity (almost exclusively related to pregnancy rather than sexually transmitted infections) to buttress mothers' own admonitions about severe, negative outcomes associated with nonmarital sexual activity. One mother said, "What I want is to go to the appointment so that the doctor can give some orientation, and I would be there to speak about how to prevent diseases ... and how to protect against having a baby" (L).

\section{DISCUSSION}

Current guidelines recommend confidential care as an essential part of health care for adolescents, ${ }^{34}$ yet many youth report no time alone with clinicians during primary care visits. ${ }^{35}$ Failure to provide opportunities for confidential care has important implications for girls' sexual health. Lack of private time during encounters is associated with lack of disclosure of sexual activity to clinicians and delay in initiation of gynecologic screening for urban girls. ${ }^{14}$ Our findings highlight barriers that must be overcome to achieve best practice regarding delivery of confidential care in urban primary care.

Our study investigated the previously unexplored area of mothers' comfort with confidential care for their adolescent daughters. The considerable discomfort expressed by mothers relates to both the content and the timing of confidential care. A key finding is that mothers saw themselves as their daughters' primary protectors against early sexual activity, pregnancy, and sexually transmitted infection, and ultimately responsible for dealing with the consequences associated with their daughters' poor reproductive outcomes. Many mothers believed that private consultations between adolescent girls and clinicians may promote risky behavior, and that confidential care undermined mothers' efforts to protect girls by challenging their mother-daughter bond.

Mothers also expressed the need to protect their daughters from the dubious influence of doctors in the clinical realm, especially from what mothers deem developmentally inappropriate information about sexual matters and sexualized physical examinations. Consistent with the distrust of the health care establishment more common among minority populations, ${ }^{36,37}$ mothers also feared unwarranted or unproven medical treatment. Of note, mothers endorsed facilitating gynecologic care and seemed willing to form alliances with physicians, but they saw the need for care as arising only after girls' sexual debut. Unfortunately, maternal awareness of sexual activity is notoriously low, ${ }^{38}$ and, indeed, girls in the current study worked hard to keep their sexual status private, leaving mothers limited in the extent to which they could truly help their daughters gain access to reproductive care.

These results provide some insight into potential strategies to improve access to confidential care. Concerns about timing relate, in part, to some misconceptions about the nature of care provided to girls before sexual debut. These misconceptions may be overcome by better education to parents and girls about anticipatory guidance and the very limited need for gynecologic examination in early adolescence. Consistently including a confidential component to visits in early adolescence with much-needed preparation for the content of these visits for both mothers and daughters may reduce the distrust and discomfort when girls begin to require reproductive care. Clinicians should provide clear information to adolescents and their parents describing the right to and limitations of confidentiality protections.

As did their mothers, adolescent girls expressed considerable discomfort with the awkwardness and sexualized nature of reproductive health care, but added fear of breach of confidentiality and the need to negotiate maternal involvement. Girls in mid to late adolescence are addressing many critical developmental tasks, including gaining autonomy from parents, developing occupational and educational goals, and becoming physically and sexually mature. ${ }^{39}$ These changes are marked by a range of events, but often overlooked is navigating 
the transition from relying on familial care to seeking independent health care. Novel approaches need to be developed and tested that help adolescents and their parents successfully accept and negotiate this key transition. Adolescents' motivation to gain adult status may be targeted in efforts to promote seeking reproductive health care, but only in ways that do not further alienate parents or increase parental resistance to the process.

Limitations of the study include the small sample of participants, all volunteers in a study addressing reproductive care. Volunteers for such a study might attribute more importance to gynecologic care than those who did not choose to participate. Our data were self-reported and subject to recall and response biases. This modest exploratory analysis was designed to provide insights and generate hypotheses for future research regarding a phenomenon that has received little research attention. Strengths include a design involving both mothers and daughters and participation of minority women in rich discussion regarding how clinicians who care for adolescents are viewed by adolescent girls and their mothers. The use of focus groups provided an opportunity for exchange among the participants, but it also may have inhibited discussion for some participants or prompted early consensus before all views were fully expressed. That the study included a small number of focus groups limited some of our conclusions, specifically those about ethnic differences and girls' reproductive health care. Additional focus groups will include some with caregivers other than mothers and groups addressing similar questions for promoting health care for adolescent boys.

No intervention can be expected to overcome entirely the inherent tension between adolescents' need for confidential care and parents discomfort with that need. Even so, our findings begin to inform how primary care interventions might be developed to enhance confidential and reproductive health care and emphasize the need to include adolescents and parents in the process. Clinicians may perceive parental discomfort related to time alone with adolescents, and they may lack skills to deal with reluctant parents or communicate the positive aspects of confidential care. Interventions will need to build on clinicians' communication skills about confidential care, while showing respect for the mothers' role as champion of her family's health care and protector of her adolescent's well-being.

To read or post commentaries in response to this article, see it online at http://www.annfammed.org/cgi/content/full/4/6/519.

Key words: Adolescents, female; mothers; sexuality; qualitative research; reproductive health

Submitted December 6, 2005; submitted, revised, March 27, 2006; accepted March 31, 2006.
Portions of these data were presented at the annual meeting of the North American Primary Care Research Group in Quebec City, October 2005.

Funding support: Funding provided by a Robert Wood Johnson Generalist Physician Faculty Scholar Award to M. Diane McKee.

\section{References}

1. Westhoff WW, McDermott RJ, Holcomb DR. HIV risk behaviors: a comparison of U.S. Hispanic and Dominican Republic youth. AIDS Educ Prev. 1996;8:106-114.

2. Tracking the Hidden Epidemics: Trends in STDs in the United States. Atlanta, Ga: Center for Disease Control and Prevention; 2000.

3. O'Donnell BL, O'Donnell CR, Stueve A. Early sexual initiation and subsequent sex-related risks among urban minority youth: the reach for health study. Fam Plann Perspect. 2001;33:268-275.

4. Ford K, Rubinstein S, Norris A. Sexual behavior and condom use among urban, low-income, African-American and Hispanic youth. AIDS Educ Prev. 1994;6:219-229.

5. Vanoss Marin B, Coyle KK, Gomez CA, Carvajal SC, Kirby DB. Older boyfriends and girlfriends increase risk of sexual initiation in young adolescents. J Adolesc Health. 2000;27:409-418.

6. Ellen JM, Aral SO, Madger LS. Do differences in sexual behaviors account for the racial/ethnic differences in adolescents' selfreported history of a sexually transmitted disease? Sex Transm Dis. 1998;25:125-129.

7. Teen sex and pregnancy. Facts in Brief. Alan Guttmacher Institute; 1999.

8. Adimora AA, Schoenbach VJ. Social context, sexual networks, and racial disparities in rates of sexually transmitted infections. J Infect Dis. 2005;191 Suppl 1:S115-122.

9. Centers for Disease Control and Prevention. CDC/HIV AIDS Fact sheet. HIVIAIDS among youth. 2006. Available at: http://www.cdc. gov/hiv/resources/factsheets/PDF/youth.pdf.

10. Ford CA, Bearman PS, Moody J. Foregone health care among adolescents. JAMA. 1999;282:2227-2234.

11. Dey A, Bloom B. Summary Health Statistics for US Children: National Health Interview Survey, 2003. Hyattsville, MD: U.S. Department of Health and Human Services, Centers for Disease Control and Prevention, National Center for Health Statistics, Division of Health Interview Statistics; 2005.

12. Klein JD, Wilson KM, McNulty M, Kapphahn C, Collins KS. Access to medical care for adolescents: results from the 1997 Commonwealth Fund Survey of the Health of Adolescent Girls. J Adolesc Health. 1999;25:120-130.

13. McKee MD, Karasz A, Weber CM. Health care seeking among urban minority adolescent girls: the crisis at sexual debut. Ann Fam Med. 2004;2:549-554.

14. McKee MD, Fletcher J, Schechter CB. Predictors of timely initiation of gynecologic care among urban adolescent girls. J Adolesc Health. 2006;39:183-191.

15. Cheng TL, Savageau JA, Sattler AL, DeWitt TG. Confidentiality in health care. A survey of knowledge, perceptions, and attitudes among high school students. JAMA. 1993;269:1404-1407.

16. Miller BC, Benson B, Galbraith KA. Family relationships and adolescent pregnancy risk: a research synthesis. Dev Review. 2001;21:1-38.

17. Mueller KE, Powers WG. Parent-child sexual discussion: perceived communicator style and subsequent behavior. Adolescence. 1990;25:469-482.

18. Miller B. Families Matter: A Research Synthesis of Family Influences on Adolescent Pregnancy. Washington, DC: National Campaign to Prevent Teen Pregnancy; 1998.

19. Guzman BL, Schlehofer-Sutton MM, Villanueva CM, et al. Let's talk about sex: how comfortable discussions about sex impact teen sexual behavior. J Health Commun. 2003;8:583-598. 
20. Romo LF, Lefkowitz ES, Sigman M, Au TK. A longitudinal study of maternal messages about dating and sexuality and their influence on Latino adolescents. J Adolesc Health. 2002;31:59-69.

21. Christopher F, Johnson D, MW R. Family, individual, and social correlates of early Hispanic adolescent sexual expression. J Sex Res. 1993;30:54-61.

22. Pick S, Palos PA. Impact of the family on the sex lives of adolescents. Adolescence. 1995;30:667-675.

23. Kotchick B, Dorsey S. Adolescent sexual risk-taking behavior in single-parent ethnic minority families. J Fam Psychol. 1999;13:93-102.

24. O'Sullivan L, Jaramillo B, Meyer-Bahlburg H. Mother-daughter communication about sexuality in a clinical sample of Hispanic adolescent girls. Hisp J Behav Sci. 1999;21:447-469.

25. Lefkowitz ES. Beyond the yes-no question: measuring parent-adolescent communication about sex. New Dir Child Adolesc Dev. 2002:43-56.

26. O'Sullivan L, Meyer-Bahlburg H, Watkins B. Mother-daughter communication about sex among urban African American and Latino families. J Adolesc Res. 2001;16:269-292.

27. Villarruel AM. Cultural influences on the sexual attitudes, beliefs, and norms of young Latina adolescents. J Soc Pediatr Nurs. 1998;3:69-79; quiz 80-61.

28. Lefkowitz ES, Romo LF, Corona R, Au TK, Sigman M. How Latino American and European American adolescents discuss conflicts, sexuality, and AIDS with their mothers. Dev Psychol. 2000;36:315-325.

29. Jaccard J, Dittus PJ. Adolescent perceptions of maternal approval of birth control and sexual risk behavior. Am J Public Health. 2000:90:1426-1430.
30. Hutchinson M, Cooney T. Patterns of parent-teen sexual risk communication: Implications for intervention. Fam Relat. 1998;47:185-194.

31. Parker R, Herdt G, Carballo M. Sexual culture, HIV transmission, and AIDS research. J Sex Res. 1991;28:77-98.

32. Berg B. Qualitative Research Methods for the Social Sciences. Needham Heights: Allyn and Bacon; 1998.

33. Miller WL, Crabtree BF. Qualitative analysis: how to begin making sense. Fam Pract Res J. 1994;14:289-297.

34. Elster A, Kuznets N. AMA Guidelines for Adolescent Preventive Services: Recommendations and Rationale. Baltimore Md: Williams and Wilkins; 1994.

35. Akinbami LJ, Gandhi H, Cheng TL. Availability of adolescent health services and confidentiality in primary care practices. Pediatrics. 2003;111:394-401.

36. Burnes Bolton L, Giger JN, Georges CA. Structural and racial barriers to health care. Annu Rev Nurs Res. 2004;22:39-58.

37. Baker R. Minority distrust of medicine: a historical perspective. $M t$ Sinai J Med. 1999;66:212-222.

38. Young TL, Zimmerman R. Clueless: parental knowledge of risk behaviors of middle school students. Arch Pediatr Adolesc Med. 1998;152:1137-1139.

39. Tapert SF, Aarons GA, Sedlar GR, Brown SA. Adolescent substance use and sexual risk-taking behavior. J Adolesc Health. 2001;28:181-189.

\section{The Annals of Family Medicine Poverty and Human Development Theme Issue Call for Papers}

The Annals of Family Medicine is joining journals worldwide to highlight problems of poverty and human development by publishing a theme issue.

This international initiative includes journals from both developed and developing countries that will simultaneously publish papers on the global theme of poverty and human development. The goal is to raise awareness, stimulate interest, and promote research on this important topic.

The Annals of Family Medicine seeks manuscripts related to this theme for publication in a November/ December 2007 theme issue. Manuscripts received before February 1, 2007, will have the best chance of being considered for the theme issue.

\section{Submission Process}

The Annals will consider original research, methodology, theory, systematic reviews, and essays pertaining to topics of poverty and human development.

- Manuscripts should be prepared in accordance with the Annals' "Instructions for Authors."

- Please submit manuscripts through the Annals' online submission system. "Instructions for Authors" and "Instructions for Submitting a Manuscript" are available at http://www.annfammed.org/misc/ifora.shtml.

- Submissions should include a cover letter that briefly describes how the paper relates to the theme of poverty and human development.

- All submissions are subject to the peer-review process.

For additional information, contact the Annals at AnnFamMed@case.edu 